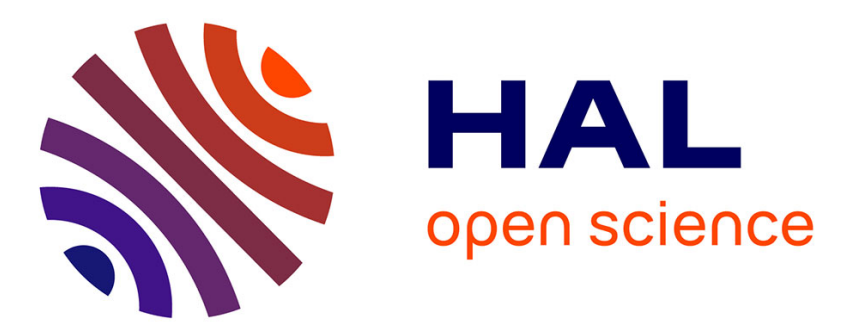

\title{
Absolute ground-state nitrogen atom density in a N2/CH4 late afterglow: TALIF experiments and modelling studies
}

Et Es-Sebbar, M C-Gazeau, Y Benilan, A Jolly, C D Pintassilgo

\section{- To cite this version:}

Et Es-Sebbar, M C-Gazeau, Y Benilan, A Jolly, C D Pintassilgo. Absolute ground-state nitrogen atom density in a N2/CH4 late afterglow: TALIF experiments and modelling studies. Journal of Physics D: Applied Physics, 2010, 43 (33), pp.335203. 10.1088/0022-3727/43/33/335203 . hal-00569677

\section{HAL Id: hal-00569677 \\ https://hal.science/hal-00569677}

Submitted on 25 Feb 2011

HAL is a multi-disciplinary open access archive for the deposit and dissemination of scientific research documents, whether they are published or not. The documents may come from teaching and research institutions in France or abroad, or from public or private research centers.
L'archive ouverte pluridisciplinaire HAL, est destinée au dépôt et à la diffusion de documents scientifiques de niveau recherche, publiés ou non, émanant des établissements d'enseignement et de recherche français ou étrangers, des laboratoires publics ou privés. 


\title{
Absolute ground-state nitrogen atom density in a $\mathrm{N}_{2} / \mathrm{CH}_{4}$ late afterglow: TALIF experiments and modeling studies
}

\author{
Et. Es-sebbar ${ }^{1}$, M. C- Gazeau ${ }^{1}$, Y. Benilan ${ }^{1}$, A. Jolly ${ }^{1}$ and C. D. Pintassilgo ${ }^{2,3}$ \\ ${ }^{1}$ LISA, Universités Paris-Est Créteil Val de Marne (UPEC) \& Paris Denis Diderot, CNRS- \\ UMR 7583, 61, avenue du Général de Gaulle, 94010 Créteil Cedex, France \\ ${ }^{2}$ Instituto de Plasmas e Fusão Nuclear-Laboratório Associado, Instituto Superior Técnico, \\ 1049-001 Lisboa, Portugal \\ ${ }^{3}$ Departamento de Engenharia Física, Faculdade de Engenharia, Universidade do Porto, \\ 4200-465 Porto, Portugal
}

Telephone: 33 (0) 145171543 / Fax: 33 (0) 145171564

E-mail: essebbar@lisa.univ-paris12.fr

Running Title: Absolute ground-state nitrogen atom density in a $\mathrm{N}_{2} / \mathrm{CH}_{4}$ late afterglow

\begin{abstract}
Following a first study on a late afterglow in flowing pure nitrogen post-discharge, we report new TALIF (Two-photon Absorption Laser-Induced Fluorescence) measurements of the absolute ground-state atomic nitrogen density $\mathrm{N}\left({ }^{4} \mathrm{~S}\right)$ and investigate the influence of methane introduced downstream from the discharge by varying the $\mathrm{CH}_{4}$ mixing ratio from 0 up to $50 \%$. The $\mathrm{N}\left({ }^{4} \mathrm{~S}\right)$ maximum density is about $2.2 \mathrm{x}$ $10^{15} \mathrm{~cm}^{-3}$ in pure $\mathrm{N}_{2}$ for a residence time of $22 \mathrm{~ms}$ and does not change significantly for methane mixing ratio up to $\sim 15 \%$, while above, a drastic decrease is observed. The influence of the residence time has been studied.

A kinetic model has been developed to determine the elementary processes responsible for the evolution of the $\mathrm{N}\left({ }^{4} \mathrm{~S}\right)$ density in $\mathrm{N}_{2} / \mathrm{CH}_{4}$ late afterglow. This model shows the same decrease as the experimental results even though absolute density values are always larger by about a factor of 3 . In the late afterglow three-body recombination dominates the loss of $\mathrm{N}\left({ }^{4} \mathrm{~S}\right)$ atoms whatever the $\mathrm{CH}_{4}$ mixing ratio. For high $\mathrm{CH}_{4}$ mixing ratio, the destruction process through collisions with $\mathrm{CH}_{3}, \mathrm{H}_{2} \mathrm{CN}$ and $\mathrm{NH}$ becomes important and is responsible for the observed decrease of the $\mathrm{N}\left({ }^{4} \mathrm{~S}\right)$ density.
\end{abstract}




\section{Introduction}

Reactive plasmas and post-discharges (afterglows) generated in pure $\mathrm{N}_{2}$ and in $\mathrm{N}_{2}-\mathrm{CH}_{4}$ gas mixture are commonly used in surface treatments like nitriding and iron nitrocarburizing [1-3]. High pressure plasma experiments using spark [4] and corona discharges [5-6] and low pressure plasma experiments using glow [7-9], radiofrequency [10-11] or microwave discharges [12-13] have been employed to reproduce the complex organic chemistry occurring in Titan's atmosphere which is mainly composed of nitrogen with a few percents of methane. According to the authors [12-13], microwave discharge plasma experiments seem to be very promising for the simulation of the processes occurring in Titan's atmosphere. Fujii and Arai [12] have used $\mathrm{CH}_{4}$ gas premixed with $\mathrm{N}_{2}$ while Pintassilgo and Loureiro [13] presented a kinetic model for the afterglow of a pure $\mathrm{N}_{2}$ flowing microwave discharge with $2 \% \mathrm{CH}_{4}$ added in the postdischarge. The advantage of the latter method is given by the possibility to vary the time at which $\mathrm{CH}_{4}$ is added in the afterglow. A large variety of species known to be present in the atmosphere of Titan were detected [13]. In the same publication, the results of a numerical simulation based on a self-consistent kinetic model are presented and discussed for discharge frequencies of 433, 915 and $2450 \mathrm{MHz}, \mathrm{N}_{2}$ pressure ranging from 0.2 to 1 Torr and for $\mathrm{CH}_{4}$ introduction times ranging from $10^{-5}$ to $10^{-3} \mathrm{~s}$.

The present paper reports the results of a similar plasma study performed in the frame of a new program of Titan's laboratory simulations (SETUP, a French acronym for Experimental and Theoretical Simulation useful for Planetology) [14-16]. Using TALIF (Two-photon Absorption Laser-Induced Fluorescence) spectroscopy, we studied the influence of the amount of methane on the $N\left({ }^{4} \mathrm{~S}\right)$ density and its variation as a function of both the discharge power and the residence time. Comparisons with numerical simulations are also presented using the same kinetic model mentioned above. Implications of this work on the development of our program of Titan's simulations conclude this paper. 


\section{Experimental arrangement}

\subsection{Plasma source}

The apparatus generating the microwave plasma with its post-discharge shown in figure 1 is similar to the one presented elsewhere [17]. Briefly, the nitrogen microwave plasma discharge is obtained in a quartz tube through a surfatron device connected to a microwave generator at $2.45 \mathrm{GHz}$ with a maximum output of $300 \mathrm{~W}$. The quartz tube ( $8 \mathrm{~mm}$ external diameter, $6 \mathrm{~mm}$ internal diameter and $50 \mathrm{~cm}$ of length) is cooled by an air gas flow and connected to a post-discharge reactor of $20 \mathrm{~cm}$ in diameter. This chamber is evacuated to about $10^{-4} \mathrm{~Pa}$ by means of a turbo-molecular pump backed by a primary rotary pump. The $\mathrm{N}_{2}$ (high purity $99.9998 \%$ ) flow rate going through the discharge varies between 100 and $500 \mathrm{sccm}$ (standard $\mathrm{cm}^{3}$ per min). The $\mathrm{N}_{2}$ gas pressure inside the post-discharge reactor is fixed at a value between 1 and 45 Torr in order to optimize the $\mathrm{N}\left({ }^{4} \mathrm{~S}\right)$ atomic density [17]. Up to 23 Torr of $\mathrm{CH}_{4}$ are injected perpendicularly to the nitrogen flow in the post-discharge reactor.

\subsection{Optical system and $N\left({ }^{4} S\right)$ atom detection and quantification}

Among the optical diagnostics that can be used to determine $\mathrm{N}\left({ }^{4} \mathrm{~S}\right)$ density in afterglow, the Two-photon Absorption Laser-Induced Fluorescence (TALIF) spectroscopy is very effective. This technique allows measuring the $\mathrm{N}\left({ }^{4} \mathrm{~S}\right)$ absolute density when completed by krypton calibration measurements [17-20]. TALIF can also provide temporal and spatial resolution [21]. Details of the apparatus to generate the UV photons needed for the TALIF measurements have been described elsewhere [17]. A Q-switched Nd:YAG laser (repetition rate $=10 \mathrm{~Hz}$, pulse-width duration=8 ns) with second harmonic generation at $532 \mathrm{~nm}$ is used to pump a dye laser system of RhB/Rh101 mixture in ethanol. The output which maximum of efficiency is observed at $615 \mathrm{~nm}$ is doubled and tripled using (KDP) and (BBO) crystals generating UV photons at 206.7 and $204.3 \mathrm{~nm}$ with a maximum energy of $4 \mathrm{~mJ}$. Those wavelengths permit two photons 
excitation of nitrogen $\left(\mathrm{N}\left(2 \mathrm{p}^{3}{ }^{4} \mathrm{~S}_{3 / 2}\right) \rightarrow \mathrm{N}\left(3 \mathrm{p}^{4} \mathrm{~S}_{3 / 2}\right)\right)$ and krypton $\left(\operatorname{Kr}\left(4 \mathrm{p}^{6}{ }^{1} \mathrm{~S}_{0}\right) \rightarrow \operatorname{Kr}\left(5 \mathrm{p},[3 / 2]_{2}\right)\right)$. The fluorescence signals are observed between 742 and $746 \mathrm{~nm}$ and at $826.3 \mathrm{~nm}$ respectively corresponding to $\mathrm{N}\left(3 \mathrm{p}{ }^{4} \mathrm{~S}_{3 / 2}\right) \rightarrow \mathrm{N}\left(3 \mathrm{~s}^{4} \mathrm{P}_{1 / 2,3 / 2,5 / 2}\right)$ and $\mathrm{Kr}\left(5 \mathrm{p},[3 / 2]_{2}\right) \rightarrow \mathrm{Kr}\left(5 \mathrm{~s}^{\prime}[1 / 2]_{1}\right)$. The photons are imaged perpendicularly to the laser beam by a lens system to the interferential filter placed in front of a photomultiplier tube detector. The time-resolved fluorescence signal is averaged and recorded by means of an acquisition system. In our study, we assume that the ground state of both species ( $\mathrm{N}$ and $\mathrm{Kr}$ ) at low UV energy is unchanged. Also, the photo-ionization processes by the absorption of a third photon as well as the amplified stimulated emission are negligible [22]. In these conditions, the absolute nitrogen atom density $n_{N}$ can be determined from the ratio of the integrated fluorescence signal $(S)$ from N $\left({ }^{4} \mathrm{~S}\right)$ atom to that of $\mathrm{Kr}\left(4 \mathrm{p}^{6}{ }^{1} \mathrm{~S}_{0}\right)$ at a known gas density $n_{K r}[17-20]$ :

$$
n_{N} \propto n_{K r}\left(S_{N} / S_{K r}\right)
$$

In our investigation, the calibration procedure has been performed in pure $\mathrm{Kr}$ with a density of $8.3 \times 10^{16}$ $\mathrm{cm}^{-3}$. The lifetimes of the $\mathrm{Kr}$ and $\mathrm{N}$ species and their quenching coefficients $\left(\mathrm{Kr}\right.$ with $\mathrm{Kr}$ and $\mathrm{N}$ with $\mathrm{N}_{2}$ and $\mathrm{CH}_{4}$ ) are taken from Niemi et al. [18].

\section{Experimental results}

TALIF measurements have been carried out as a function of the energy of the pulse laser in various experimental conditions (figure 2): (a) with pure $\mathrm{N}_{2}$ (b) $2 \% \mathrm{CH}_{4} / \mathrm{N}_{2}$ and (c) with pure $\mathrm{Kr}$ for the calibration procedure. At low laser energy, the slope of the linear fit in log-log plot is $(2.0 \pm 0.1)$, in agreement with a two-photon absorption process. Saturation is observed at higher energy, above 150, 210 and $65 \mu \mathrm{J}$ respectively for measurements (a), (b) and (c). In order to avoid any saturation, all nitrogen and $\mathrm{Kr}$ measurements have been carried out respectively at 120 and $40 \mu \mathrm{J}$.

The measurements of $\mathrm{N}\left({ }^{4} \mathrm{~S}\right)$ density as a function of the microwave discharge power are presented in figure 3 for different percentages of methane: $\left(2 \%, 10 \%\right.$ and 20\%). Results obtained in pure $\mathrm{N}_{2}$ are also 
displayed for comparison. All curves show the $\mathrm{N}\left({ }^{4} \mathrm{~S}\right)$ density increasing with the microwave power and reaching a plateau above $90 \mathrm{~W}$. We have therefore chosen in the following measurements a discharge power of $100 \mathrm{~W}$ in order to optimize the nitrogen density value. Note that the maximum density in pure $\mathrm{N}_{2}$ reaches $2.2 \times 10^{15} \mathrm{~cm}^{-3}$ and the addition of methane lowers this value down to $0.9 \times 10^{15} \mathrm{~cm}^{-3}$ for a methane mixing ratio of $20 \%$.

Figure 4 shows the measured absolute $\mathrm{N}\left({ }^{4} \mathrm{~S}\right)$ density obtained at fixed discharge power $(100 \mathrm{~W})$ as a function of the methane mixing ratio for different flow rate (sccm)/pressure (Torr): 500/22, 200/16 and 100/12 (i.e. corresponding to residence times of 22, 41 and $61 \mathrm{~ms}$ respectively). As already described in [17], the $\mathrm{N}\left({ }^{4} \mathrm{~S}\right)$ density decreases with the increasing residence time. The addition of $\mathrm{CH}_{4}$ in the late afterglow induces no significant effect on the $\mathrm{N}\left({ }^{4} \mathrm{~S}\right)$ atomic density up to about $15 \%$ confirming and extending the results obtained by Pintassilgo et al [3] for a $\mathrm{CH}_{4}$ proportion less than $1 \%$ in $\mathrm{N}_{2}$. For larger methane mixing ratio (above 15\%), a rapid decrease of the $\mathrm{N}\left({ }^{4} \mathrm{~S}\right)$ atomic density is observed. To understand this behavior, the kinetic model presented in $[3,13]$ is adapted for our experimental conditions as described in the following paragraph.

\section{Model}

\subsection{Description}

The calculations are based on self-consistent solutions of the homogeneous electron Boltzmann equation coupled to a system of rate balance equations for the most important neutrals and charged species produced inside the pure nitrogen microwave discharge. The end of the discharge occurs when electron density reaches the critical value of $3.74 \times 10^{11} \mathrm{~cm}^{-3}$ (calculated at $2.45 \mathrm{GHz}$ and for a quartz tube) $[3,23]$. The concentrations of the various active species determined at this moment are used as initial conditions for the modelling of the post discharge. The evolution of the system in the early afterglow is calculated by considering the relaxation of the same system of master balance equations. The introduction of methane into the post-discharge at $25 \mathrm{~cm}$ downstream from the end of the discharge (see figure 1) can then be 
modeled by solving a system of time-varying kinetic rate-balance equations for different species produced in a $\mathrm{N}_{2}-\mathrm{CH}_{4}$ gas mixture. The model for the active discharge region takes into account the vibrationally excited states of molecular nitrogen $\left(\mathrm{N}_{2}\left(\mathrm{X}^{1} \Sigma_{\mathrm{g}}^{+}, \mathrm{v}\right)\right)$, the electronically excited states of molecular nitrogen $\left(\mathrm{N}_{2}(\mathrm{~A}), \mathrm{N}_{2}(\mathrm{~B}), \mathrm{N}_{2}(\mathrm{C}), \mathrm{N}_{2}\left(\mathrm{a}^{\prime}\right), \mathrm{N}_{2}(\mathrm{a})\right.$, and $\left.\mathrm{N}_{2}(\mathrm{w})\right)$, both ground and excited states of atomic nitrogen $\left(\mathrm{N}\left({ }^{4} \mathrm{~S}\right)\right.$, $\mathrm{N}\left({ }^{2} \mathrm{D}\right)$, and $\left.\mathrm{N}\left({ }^{2} \mathrm{P}\right)\right)$ and the $\mathrm{N}_{2}{ }^{+}$and $\mathrm{N}_{4}{ }^{+}$ions. In addition to those species, the master equations used to describe the mixture in the post-discharge region consider the $\mathrm{CH}_{4}$ fragments together with species produced by reactions with $\mathrm{N}_{2}$ (see references [8] and [13] for further details). The model also includes surface reactions, in particular the wall recombination probability for the nitrogen atoms which is equal to $2.1 \times 10^{-4}$ (referred below in table 2 as $\mathrm{d} 6$ ) as determined in our recent publication [17].

\subsection{Results and discussion}

Model results are presented in figure 4 and compared to experimental ones. They are systematically a factor of 3 larger than the experimental data. This can be due to the fact that the flow rates are so important that stationary conditions are not reached at the end of the discharge. Consequently, the absolute $\mathrm{N}\left({ }^{4} \mathrm{~S}\right)$ density is critically dependent on the initial conditions taken at the beginning of the afterglow. In contrast, the experimental and theoretical curves show a very similar behaviour towards the increasing methane mixing ratio.

\begin{tabular}{ll}
\hline $\begin{array}{l}\text { Reaction } \\
\text { name }\end{array}$ & \multicolumn{1}{c}{ Processes } \\
\hline p1 & $\mathrm{N}\left({ }^{2} \mathrm{P}\right)+\mathrm{N}_{2}\left(\mathrm{X}^{1} \Sigma_{\mathrm{g}}^{+}, \mathrm{v}=0\right) \rightarrow \mathrm{N}\left({ }^{4} \mathrm{~S}\right)+\mathrm{N}_{2}$ \\
p2 & $\mathrm{N}_{2}\left(\mathrm{X}^{1} \Sigma_{\mathrm{g}}^{+}, 10<\mathrm{v}<25\right)+\mathrm{N}_{2}\left(\mathrm{X}^{1} \Sigma_{\mathrm{g}}^{+}, 10<\mathrm{v}<25\right) \rightarrow 2 \mathrm{~N}\left({ }^{4} \mathrm{~S}\right)+\mathrm{N}_{2}\left(\mathrm{X}^{1} \Sigma_{\mathrm{g}}^{+}, \mathrm{v}=0\right)$ \\
p3 & $\mathrm{N}\left({ }^{2} \mathrm{P}\right)+\mathrm{N}\left({ }^{4} \mathrm{~S}\right) \rightarrow 2 \mathrm{~N}\left({ }^{4} \mathrm{~S}\right)$ \\
p4 & $\mathrm{N}\left({ }^{2} \mathrm{P}\right)+\mathrm{N}_{2}\left(\mathrm{X}^{1} \Sigma_{\mathrm{g}}^{+}, \mathrm{v} \geq 10\right) \rightarrow \mathrm{N}\left({ }^{4} \mathrm{~S}\right)+\mathrm{N}_{2}\left(\mathrm{~A}^{3} \Sigma_{\mathrm{u}}^{+}\right)$ \\
p5 & $\mathrm{N}_{2}\left(\mathrm{~A}^{3} \Sigma_{\mathrm{u}}^{+}\right)+\mathrm{N}_{2}\left(\mathrm{X}^{1} \Sigma_{\mathrm{g}}^{+}, 15 \leq \mathrm{v} \leq 19\right) \rightarrow 2 \mathrm{~N}\left({ }^{4} \mathrm{~S}\right)+\mathrm{N}_{2}$
\end{tabular}

Table 1. Main populating mechanisms of $\mathrm{N}\left({ }^{4} \mathrm{~S}\right)$ atoms under the conditions of the present work 


\begin{tabular}{ll}
\hline \hline $\begin{array}{l}\text { Reaction } \\
\text { name }\end{array}$ & \multicolumn{1}{c}{ Processes } \\
\hline $\mathrm{d} 1$ & $\mathrm{~N}\left({ }^{4} \mathrm{~S}\right)+\mathrm{N}\left({ }^{4} \mathrm{~S}\right)+\mathrm{N}_{2} \rightarrow \mathrm{N}_{2}+\mathrm{N}_{2}(\mathrm{~B})$ \\
$\mathrm{d} 2$ & $\mathrm{~N}\left({ }^{4} \mathrm{~S}\right)+\mathrm{N}_{2}\left(\mathrm{~A}^{3} \Sigma_{\mathrm{u}}^{+}\right) \rightarrow \mathrm{N}_{2}\left(\mathrm{X}^{1} \Sigma_{\mathrm{g}}^{+}, 6 \leq \mathrm{v} \leq 9\right)+\mathrm{N}\left({ }^{2} \mathrm{P}\right)$ \\
$\mathrm{d} 3$ & $\mathrm{~N}\left({ }^{4} \mathrm{~S}\right)+\mathrm{CH}_{3} \rightarrow \mathrm{H}_{2} \mathrm{CN}+\mathrm{H}$ \\
$\mathrm{d} 4$ & $\mathrm{~N}\left({ }^{4} \mathrm{~S}\right)+\mathrm{H}_{2} \mathrm{CN} \rightarrow \mathrm{HCN}+\mathrm{NH}$ \\
$\mathrm{d} 5$ & $\mathrm{~N}\left({ }^{4} \mathrm{~S}\right)+\mathrm{NH} \rightarrow \mathrm{N}_{2}\left(\mathrm{X}^{1} \Sigma_{\mathrm{g}}^{+}, \mathrm{v}=0\right)+\mathrm{H}$ \\
$\mathrm{d} 6$ & $\mathrm{~N}\left({ }^{4} \mathrm{~S}\right)+$ wall $\rightarrow 1 / 2 \mathrm{~N}_{2}\left(\mathrm{X}^{1} \Sigma_{\mathrm{g}}^{+}, \mathrm{v}=0\right)$
\end{tabular}

Table 2. Main depopulating mechanisms of $\mathrm{N}\left({ }^{4} \mathrm{~S}\right)$ atoms in the conditions of the present work

In order to explain the observed evolution of the $\mathrm{N}\left({ }^{4} \mathrm{~S}\right)$ density as a function of the methane mixing ratio in the range $0-50 \%$, we have identified the contribution of the main reactions of production (table 1) and loss (table 2) of this specie. Figure 5 (a) presents the relative contribution of the different $\mathrm{N}\left({ }^{4} \mathrm{~S}\right)$ production processes calculated for a residence time of $22 \mathrm{~ms}$ (corresponding to a flow rate of $500 \mathrm{sccm}$ and pressure of 22 Torr) as a function of the methane mixing ratio. The production of $\mathrm{N}\left({ }^{4} \mathrm{~S}\right)$ atoms is mainly due to collisions between metastable $\mathrm{N}\left({ }^{2} \mathrm{P}\right)$ and $\mathrm{N}_{2}\left(\mathrm{X}{ }^{1} \Sigma_{\mathrm{g}}{ }^{+}, \mathrm{v}\right)$ (reaction $\left.\mathrm{p} 1\right)$, and the reaction between two molecules $\mathrm{N}_{2}\left(\mathrm{X}^{1} \Sigma_{\mathrm{g}}{ }^{+}, 10<\mathrm{v}<25\right)$ (reaction $\left.\mathrm{p} 2\right)$. The latter process becomes the major pathway above $15 \%$ of methane while $\mathrm{p} 1$ decreases and becomes less important. In comparison to $\mathrm{p} 1$ and $\mathrm{p} 2$, the contributions of the other reactions (p3, p4 and p5) are always negligible. The decrease of p1 results essentially from the fact that $\mathrm{N}_{2}\left(\mathrm{~A}^{3} \Sigma_{\mathrm{u}}^{+}\right)$is strongly quenched by methane during the afterglow through reactions $\mathrm{N}_{2}\left(\mathrm{~A}^{3} \Sigma_{\mathrm{u}}^{+}\right)+\mathrm{CH}_{4}->\mathrm{N}_{2}\left(\mathrm{X}^{1} \Sigma_{\mathrm{g}}{ }^{+}, \mathrm{v}\right)+\mathrm{CH}_{3}+\mathrm{H}$ and $\rightarrow \mathrm{N}_{2}\left(\mathrm{X}^{1} \Sigma_{\mathrm{g}}{ }^{+}, \mathrm{v}\right)+\mathrm{CH}_{2}+\mathrm{H}_{2}$. Hence, as the amount of methane introduced into the post-discharge increases, the population of $\mathrm{N}_{2}\left(\mathrm{~A}^{3} \Sigma_{\mathrm{u}}^{+}\right)$decreases. This also leads to a decrease of the concentration of $\mathrm{N}\left({ }^{2} \mathrm{P}\right)$ since this species is mostly produced via the reaction $\mathrm{N}\left({ }^{4} \mathrm{~S}\right)+\mathrm{N}_{2}\left(\mathrm{~A}^{3} \Sigma_{\mathrm{u}}^{+}\right) \rightarrow \mathrm{N}_{2}\left(\mathrm{X}^{1} \Sigma_{\mathrm{g}}^{+}, 6 \leq \mathrm{v} \leq 9\right)+\mathrm{N}\left({ }^{2} \mathrm{P}\right)$ (designated by $\mathrm{d} 2$ in table 2 ).

Figure 5 (b) presents the relative contribution of $\mathrm{N}\left({ }^{4} \mathrm{~S}\right)$ loss processes as a function of the methane mixing ratio for the same residence time and pressure than the previous figure. We can observe that the three body recombination (reaction d1) is predominant but decreases slowly when $\mathrm{CH}_{4}$ is added. The collisions of $\mathrm{N}$ $\left({ }^{4} \mathrm{~S}\right)$ with $\mathrm{N}_{2}\left(\mathrm{~A}^{3} \Sigma_{\mathrm{u}}{ }^{+}\right)$(reaction $\left.\mathrm{d} 2\right)$ is the second most important pathway and also decreases when the 
$\mathrm{CH}_{4}$ mixing ratio increases. Three other depopulating processes, reactions $\mathrm{d} 3, \mathrm{~d} 4$ and $\mathrm{d} 5$, correspond to collisions of $\mathrm{N}\left({ }^{4} \mathrm{~S}\right)$ with $\mathrm{CH}_{3}, \mathrm{H}_{2} \mathrm{CN}$ and $\mathrm{NH}$ which are produced by the dissociation of $\mathrm{CH}_{4}$ reacting with metastable $\mathrm{N}_{2}\left(\mathrm{~A}^{3} \Sigma_{\mathrm{u}}{ }^{+}\right)$and $\mathrm{N}\left({ }^{2} \mathrm{D}\right)$ atoms (see [3] for details). Note that the contribution of the two processes $\mathrm{d} 4$ and $\mathrm{d} 5$ to the loss of $\mathrm{N}\left({ }^{4} \mathrm{~S}\right)$ atoms is similar. As the percentage of methane increases, the relative contribution of these three processes becomes more important.

While $\mathrm{d} 5$ restores $\mathrm{N}\left({ }^{4} \mathrm{~S}\right)$, the reaction $\mathrm{d} 3$ followed by $\mathrm{d} 4$ leads to the production of HCN which definitively traps nitrogen. Therefore the concentration of nitrogen atoms decreases for high $\mathrm{CH}_{4}$ mixing ratios as shown in figure 4 .

Performed for longer residence times (i.e. 41 and $61 \mathrm{~ms}$, corresponding to pressures of 16 and 12 Torr), similar contributions of the $\mathrm{N}\left({ }^{4} \mathrm{~S}\right)$ production and loss are obtained except for the loss through wall surface recombination (reaction d6). Indeed, the loss of nitrogen atoms at the reactor's surface becomes significant for longer residence time, as a result lower pressure working conditions. Figure 6 shows that the value of the contribution of $\mathrm{d} 6$ reaches $12 \%$ for a residence time of $61 \mathrm{~ms}$ compared to $1 \%$ for $22 \mathrm{~ms}$ (figure 5). This result is consistent with the variation of the maximum of $\mathrm{N}\left({ }^{4} \mathrm{~S}\right)$ density as a function of the residence time (figure 4).

In spite of the qualitative agreement between experiment and modeling, the calculated densities for nitrogen atoms in the afterglow are in general larger than the measured ones. This can be due to several causes. First, the present simulations assume homogeneous discharge and afterglow regions. This hypothesis seems reasonable in the case of the microwave plasma where the tube has an inner diameter of $6 \mathrm{~mm}$. But, in the afterglow region the experimental measurements were performed in a reactor that has a $200 \mathrm{~mm}$ inner diameter. Under these conditions, the heavy species may present radial profiles, which are not taken into account by the present model. Secondly, we have considered constant values of the gas temperature in the discharge $(\sim 1000 \mathrm{~K})$ and post-discharge $(300 \mathrm{~K})$ regions. Thus, we have not taken into account temperature gradient at the end of the discharge. This simplification affects the rate coefficients associated with vibration-vibration $(\mathrm{V}-\mathrm{V})$ and vibration-translation $(\mathrm{V}-\mathrm{T})$ processes, which play an 
important role in the temporal evolution of the vibrational distribution function (VDF), which in turn affect the populating and depopulating mechanisms of nitrogen atoms in the afterglow.

\section{Conclusion}

The present studies have been performed in the frame of the development of Titan simulation programs called SETUP (a French acronym for Experimental and Theoretical Simulation useful for Planetology). Titan's atmospheric neutral chemistry is driven by electrons from Saturn's magnetosphere and solar UV photons. Until now, the simulations involved only one energy source, i.e. electrons or photons (see recent works [24] and [25] respectively). Thus, a dedicated device has been developed using plasma discharge to dissociate $\mathrm{N}_{2}$ and photons for $\mathrm{CH}_{4}$ photolysis (continuous Lyman $\alpha$ or pulsed $248 \mathrm{~nm}$ irradiations) [16].

In this paper, we have studied the evolution of absolute $\mathrm{N}\left({ }^{4} \mathrm{~S}\right)$ density in late afterglow $\mathrm{N}_{2}$ microwave discharge when different methane mixing ratios are introduced. Experimental and theoretical results agree showing that the $\mathrm{N}\left({ }^{4} \mathrm{~S}\right)$ density does not vary significantly up to $\sim 15 \%$ of methane mixing ratio before decreasing drastically. The remaining discrepancy between model and experiments concerns the absolute density can be explained by the uncertainty on the initial conditions to be considered in the model. In spite of this disagreement, the synergy between modelling simulations and the experiments allows to explain the diminution of $\mathrm{N}\left({ }^{4} \mathrm{~S}\right)$ density with increasing $\mathrm{CH}_{4}$ mixing ratio. The present results confirm experimentally and extend the conclusions that were obtained in previous theoretical studies $[3,13]$ : methane reacts with metastable energetic nitrogen species when introduced in the $\mathrm{N}_{2}$ post discharge zone, and a complex chemistry leading mainly to $\mathrm{HCN}$ is initiated. Owing to this new study, we are now aware that, especially when introduced with a high mixing ratio, the methane dissociation through the flowing plasma plays a role in the production of numerous compounds suspected to be also produced during its photo-dissociation. Thus, we will be able to disentangle the relative contribution of both mechanisms when the SETUP simulations (including photolysis) will be carried out. 
Acknowledgment. This work is developed in the frame of the SETUP (a French acronym for Experimental and Theoretical Simulations Useful for Planetology) program. The support of this research by French Space Agency (Centre National d'Etudes Spatiales, CNES), from the Ile de France Region (SESAME grant) and the French National Program of Planetary Sciences (PNP) is gratefully acknowledged. The main author acknowledges the Centre National de la Recherche Scientifique (CNRS) for its post-doctoral grant. 


\section{References}

[1] Ricard A, Oseguera-Pena J. E, Falk L, Michel H and Gantois M 1990 Active species in microwave postdischarge for steel-surface nitriding IEEE Trans. Plasma Sci. 18, 940

[2] Michel H, Czerwiec T, Gantois M, Ablitzer D and Ricard A 1995 Progress in the analysis of the mechanisms of ion nitriding Surf. Coat. Technol. 72103

[3] Pintassilgo C D, Jaoul C, Loureiro J, Belmonte T and Czerwiec T 2007 Kinetic modelling of a $\mathrm{N}_{2}$ flowing microwave discharge with $\mathrm{CH}_{4}$ addition in the post-discharge for nitrocarburizing treatments J. Phys. D Appl. Phys. 40 3620-3632

[4] Vanssay E De, Gazeau M.-C, Guillemin J-C and Raulin F 1995 Experimental simulation of Titan's organic chemistry at low temperature Planetary and Space Science $\mathbf{4 3}$ 25-31

[5] Ramírez S I, Navarro-González R, Coll P and Raulin F 2001 Possible contribution of different energy sources to the production of organics in Titan's atmosphere Advances in Space Research 27 261-270

[6] Horvath G, Skalny J D, Mason N J, Klas M, Zahoran M, Vladoiu R and Manole M 2009 Corona discharge experiments in admixtures of $\mathrm{N}_{2}$ and $\mathrm{CH}_{4}$ : a laboratory simulation of Titan's atmosphere Plasma sources Sci. Technol. 18034016

[7] Coll P, Coscia D., Smith N., Gazeau M.-C., Ramirez S I, Cernogora G., G Israël, and Raulin F 1999 Experimental laboratory simulation of Titan's atmosphere: aerosols and gas phase Planetary and Space Science $\mathbf{4 7}$ 1331-1340

[8] Pintassilgo C D, Loureiro J, Cernogora G and Touzeau M 1999 Methane decomposition and active nitrogen in a $\mathrm{N}_{2}-\mathrm{CH}_{4}$ glow discharge at low pressure Plasma sources Sci. Technol. 8 463478

[9] Bernard J.-M, Coll P, Coustenis A, Raulin F 2003 Experimental simulation of Titan's atmosphere: Detection of ammonia and ethylene oxide Planetary and Space Science 511003 - 1011

[10] Szopa C, Cernogora G, Boufendi L, Correia J J and Coll P 2006 PAMPRE: a dusty plasma experiment for Titan's tholins production and study Planetary and space Science 54 394-404

[11] Imanaka H, Khare B N, Elsila J E, Bakes E L O, McKay C P, Cruikshank D P, Sugita S, Matsui T and Zare R N 2004 laboratory experiments of Titan's tholin formed in cold plasma at various 
pressures: implication for nitrogen-containing polycyclic aromatic compounds in Titan's haze Icarus 168 344-366

[12] Fujii T and Arai N 1999 Analysis of N-containing Hydrocarbon Species Produced by a $\mathrm{CH}_{4} / \mathrm{N}_{2}$ Microwave Discharge: Simulation of Titan's Atmosphere ApJ 519858

[13] Pintassilgo C. D. and Loureiro J 2009 Production of hydrocarbons and nitriles using a $\mathrm{N}_{2}-\mathrm{CH}_{4}$ afterglow plasma for simulation of Titan's atmosphere Planetary and Space Science 57, 16211630

[14] Romanzin C, Gazeau M.-C, Benilan Y, Hébrard E, Jolly A, Raulin F, Boyé-Peronne S, Douin S and Gauyacq D 2005 Methane photochemistry: a brief review in the frame of a new experimental of Titan's atmosphere simulations Advances in Space Research 36 258-267

[15] Romanzin C, Benilan Y, Jolly A and Gazeau M.-C. 2008 Photolytic behaviour of methane at Lyman-alpha and $248 \mathrm{~nm}$ : Studies in the frame of a simulation program of Titan's atmosphere (SETUP) Advances in Space Research 42 2036-2044

[16] Romanzin C, Arzoumanian E, Es-sebbar Et, Jolly A, Perrier S, Gazeau M.-C, Benilan Y 2010 Combined experimental and theoretical studies on methane photolysis at $121.6 \mathrm{~nm}$ and $248 \mathrm{~nm}-$ implications on a program of laboratory simulations of Titan's atmosphere Planetary and Space Science, in press

[17] Es-sebbar Et, Benilan Y, Jolly A and Gazeau M-C 2009 Characterization of an $\mathrm{N}_{2}$ flowing microwave post-discharge by OES spectroscopy and determination of absolute ground state nitrogen atom densities by TALIF Spectroscopy J. Phys. D: Applied Physics $\mathbf{4 2} 135206$

[18] Niemi K, Schulz-von der Gathen V and Döbele H F 2001 Absolute calibration of atomic density measurements by laser-induced fluorescence spectroscopy with two-photon excitation J. Phys. D: Appl. Phys., 34 2330-2335

[19] Es-sebbar Et, Sarra-Bournet C, Naudé N, Massines F and Gherardi N 2009 Absolute nitrogen atom density measurements by two-photon laser-induced fluorescence spectroscopy in atmospheric pressure dielectric barrier discharges of pure nitrogen J. Appl. Phys. 106073302

[20] Mazouffre S, Foissac C, Supiot P, Engeln R, Vankan P. J. W, Schram D. C, and Sadeghi N 2001 Density and temperature of $\mathrm{N}$ atoms in the afterglow of a microwave discharge measured by a two-photon laser-induced fluorescence technique Plasma Sources Sci. Technol. 10 168-175

[21] Lukas C, Spaan M, Schulz-von der Gathen V, Thmoson M, Wegst R, Döbele H F and Neiger M 2001 Dielectric barrier discharges with steep voltage rise: mapping of atomic nitrogen in single 
filaments measured by laser-induced fluorescence spectroscopy Plasma Sources Sci. Technol. 10 $445-450$

[22] Amorim J, Baravian G and Jolly J 2000 Laser-induced resonance fluorescence as a diagnostic technique in non-thermal equilibrium plasmas J Phys. D: Appl. Phys., 33 R51-R65

[23] Shivarova A and Zhelyakov I 1978 Surface waves in a homogeneous plasma sharply bounded by a dielectric Plasma Phys. 201049

[24] Carrasco N, Schmitz-Afonso I, Bonnet J-Y, Quirico E, Thissen R, Dutuit O, Bagag A, Laprévote O, Buch A, Giulani A, Adande G, Ouni F, Hadamcik E, Szopa C and Cernogora G 2009 Chemical Characterization of Titan's Tholins: Solubility, Morphology and Molecular Structure Revisited $J$. Phys. Chem. A. 113 11195-11203

[25] Imanaka H and Smith MA 2009 EUV photochemical production of unsaturated hydrocarbons: implication to EUV photochemistry in Titan and Jovian planets J. Phys. Chem. A. $11311187-$ 11194 
Figures

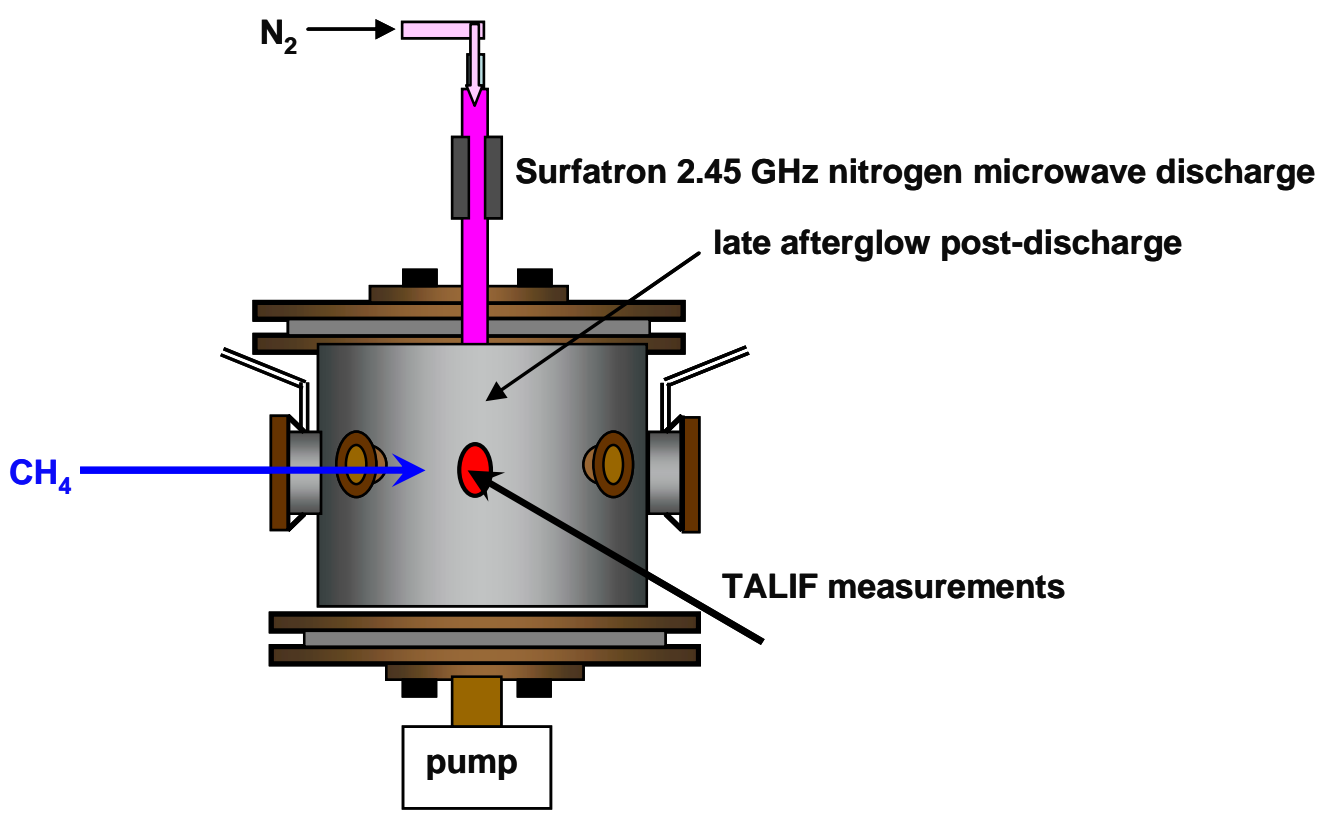

Figure 1. Experimental set up for the investigation of the microwave flowing post-discharge afterglow by TALIF spectroscopy. 


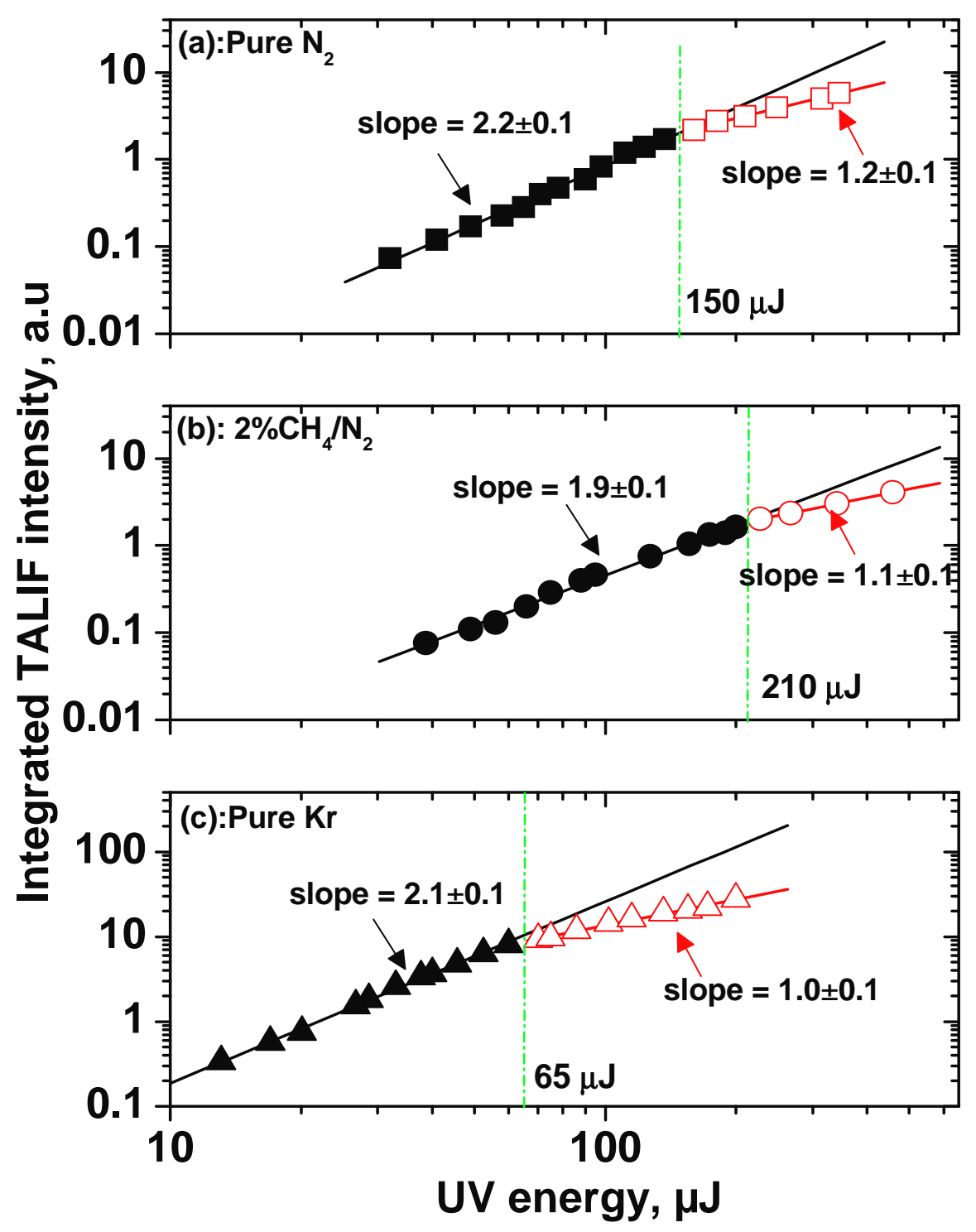

Figure 2. $\log$ - $\log$ plot of $\mathrm{N}\left({ }^{4} \mathrm{~S}\right)$-TALIF in: (a) in pure $\mathrm{N}_{2}$, (b) $2 \% \mathrm{CH}_{4} / \mathrm{N}_{2}$ and $\mathrm{Kr}\left({ }^{1} \mathrm{~S}_{0}\right)$-TALIF in (c) pure Kr. TALIF measurements in pure $\mathrm{N}_{2}$ and $\mathrm{N}_{2} / \mathrm{CH}_{4}$ mixtures have performed for a discharge power of $100 \mathrm{~W}$ and a gas pressure of 22 Torr. TALIF calibration with krypton has been made without discharge for a gas pressure of 2.3 Torr. 


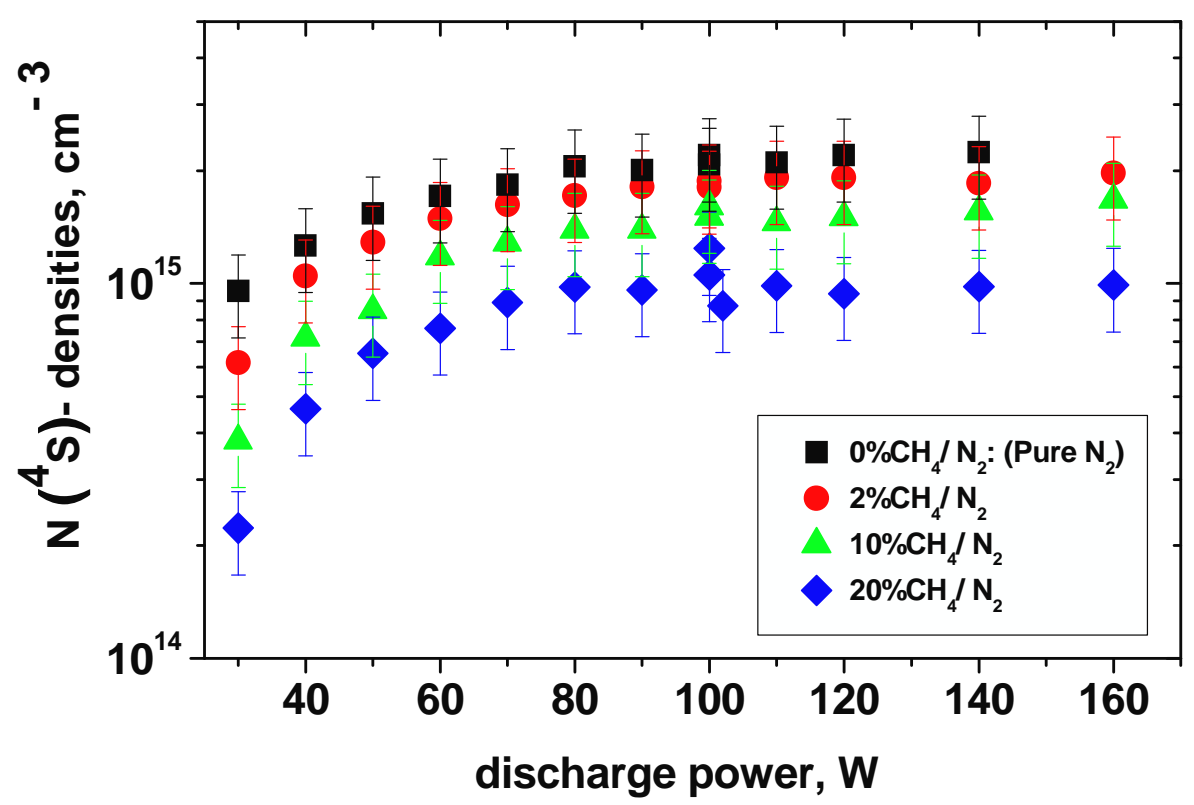

Figure 3. Absolute densities of $\mathrm{N}\left({ }^{4} \mathrm{~S}\right)$ atoms in $\mathrm{N}_{2} / \mathrm{CH}_{4}$ mixture as a function of the microwave discharge power for $\mathrm{N}_{2}$ gas flow rate $=500 \mathrm{sccm}$ and pressure=22 Torr (residence time $=22 \mathrm{~ms}$ ) and for percentages of $\mathrm{CH}_{4}$ added in late afterglow of $2 \%$ (dots), $10 \%$ (triangles) and $20 \%$ (diamonds). The $\mathrm{N}\left({ }^{4} \mathrm{~S}\right)$ density measured in pure $\mathrm{N}_{2}$ is also shown for comparison (squares). 


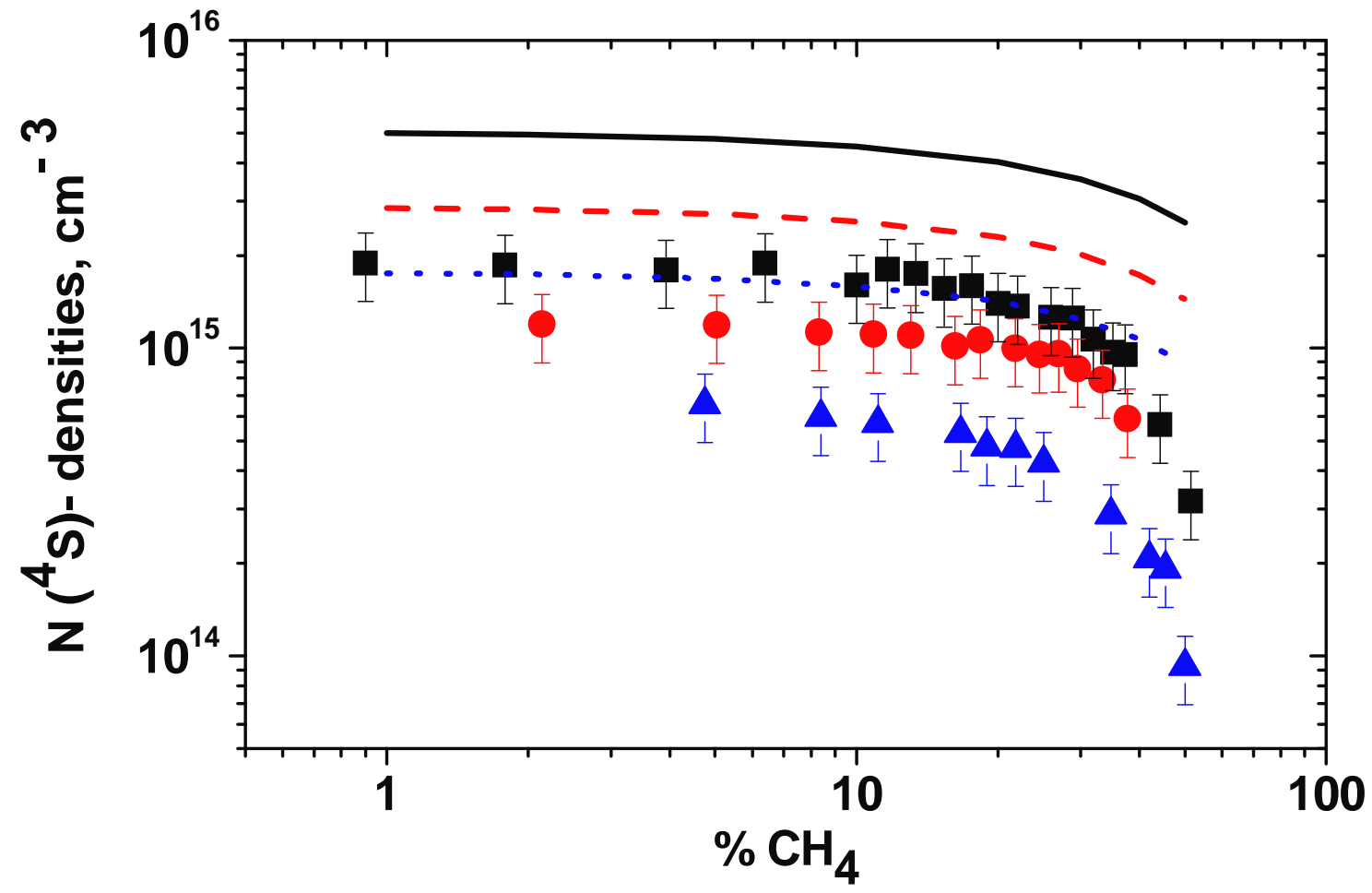

Figure 4. Measured (symbols) and theoretical (lines) reporting the absolute densities of $\mathrm{N}\left({ }^{4} \mathrm{~S}\right)$ atoms in $\mathrm{N}_{2} / \mathrm{CH}_{4}$ mixture as a function of the $\mathrm{CH}_{4}$ mixing ratio injected in the late afterglow for different flow rate (sccm)/pressure (Torr) of 500/22, 200/16 and 100/12 corresponding to residence times of $22 \mathrm{~ms}$ ( $\boldsymbol{\bullet}$, black line), $41 \mathrm{~ms}(\bullet$, red dashes line) and $61 \mathrm{~ms}(\boldsymbol{\Lambda}$, blue dotted line), respectively. The microwave discharge power is $100 \mathrm{~W}$. 

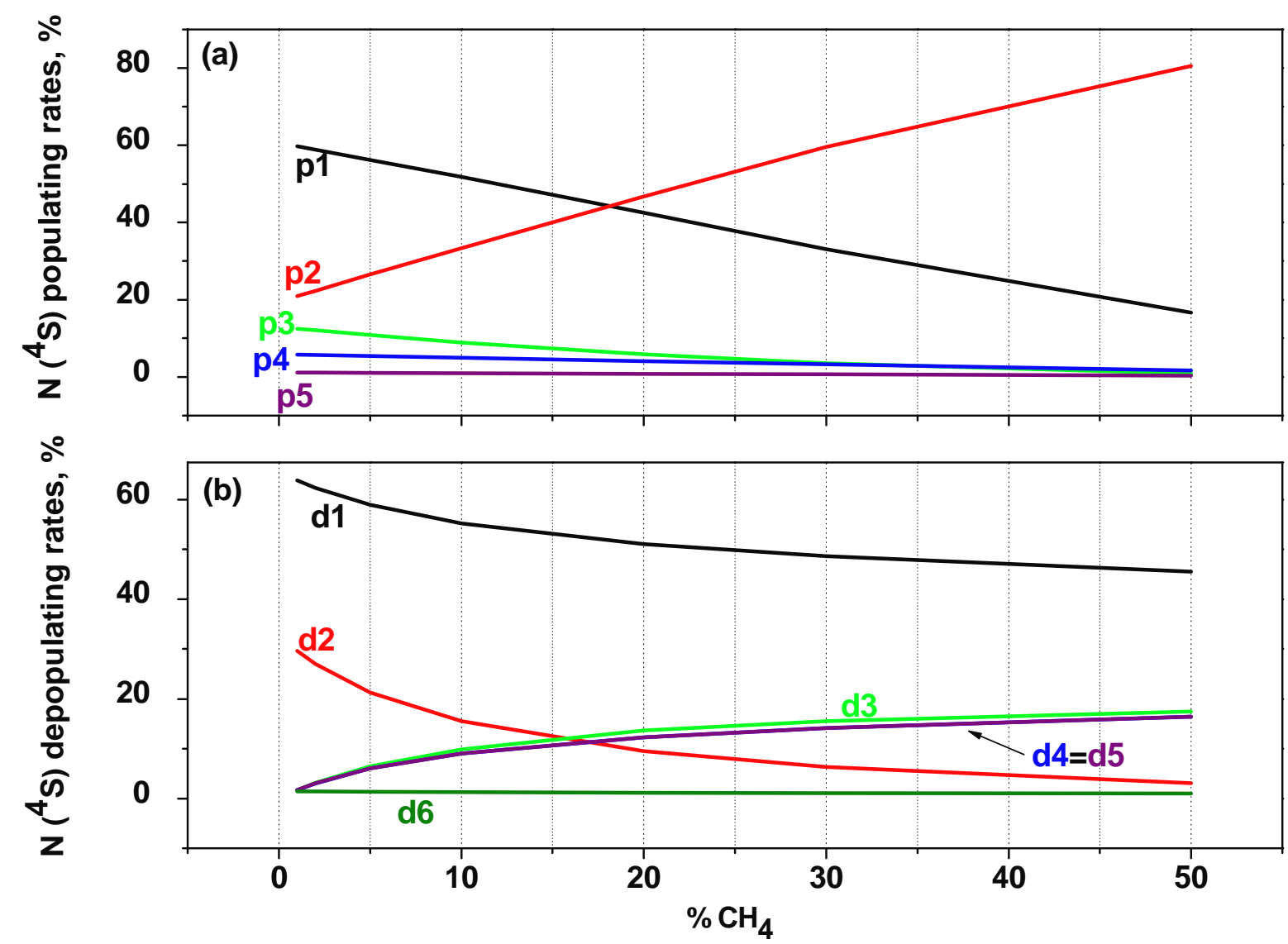

Figure 5. Calculated relative contribution of the rate leading to the (a) production and (b) loss of $\mathrm{N}\left({ }^{4} \mathrm{~S}\right)$ atoms as a function of the $\mathrm{CH}_{4}$ mixing ratio as listed in tables 1 and 2 , respectively. The calculation is performed in the same conditions such as results of figure 4 in the case of $22 \mathrm{~ms}$ of afterglow time. 


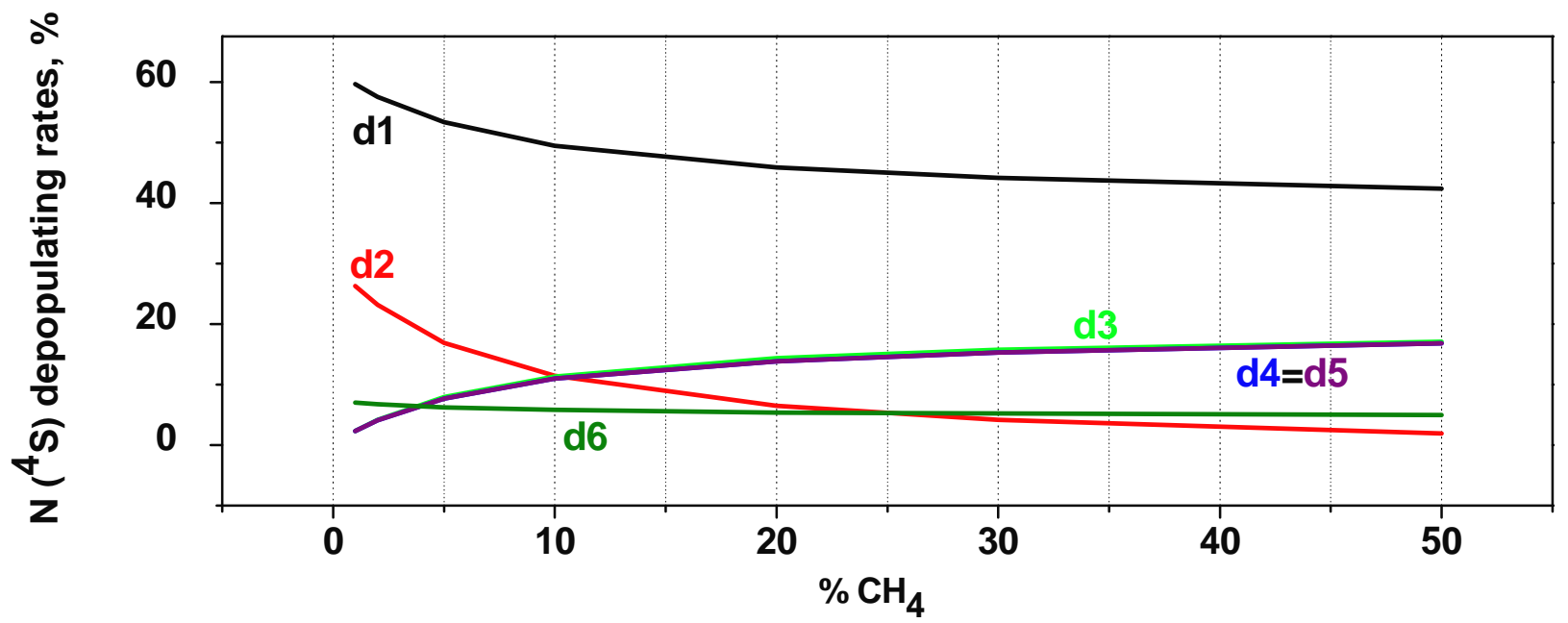

Figure 6. Calculated relative contribution of the rate leading to the loss of $\mathrm{N}\left({ }^{4} \mathrm{~S}\right)$ atoms as a function of the $\mathrm{CH}_{4}$ mixing ratio as listed in table 2. The calculation is performed in the same conditions such as results of figure 4 in the case of $61 \mathrm{~ms}$ of afterglow time. 